\title{
WAHDAH ISLAMIYAH DALAM MEMBENTUK KARAKTER MASYARAKAT DI KOTA KENDARI
}

\author{
${ }^{1 *}$ Nanang Purwana, ${ }^{2}$ Nasruddin Suyuti, ${ }^{3}$ Abdul Halim Momo
}

Program Studi Kajain Budaya Pascasarjana, Universitas Halu Oleo, Kendari

Jurusan Antropologi, Fakultas Budaya Universitas Halu Oleo, Kendari

Jurusan Pendidikan Pancasila dan Kewarganegaraan, Fakultas Pendidikan dan Ilmu

Keguruan Universitas Halu Oleo, Kendari

\section{Corresponding Author: * Nanang Purwana (nanangpurwana12@gmail.com)}

\begin{abstract}
Tujuan penelitian ini adalah untuk mendeskripsikan bentuk-bentuk, fungsi, nilai-nilai, dan perubahan akhlak masyarakat Kota Kendari setelah mendapatkan pendidikan akhlak/karakter yang diberikan oleh Wahdah Islamiyah. Data dalam penelitian ini diperoleh melalui observasi dan wawancara secara terstruktur terhadap 12 orang pengurus Wahdah Islamiyah Kendari dan 17 orang masyarakat Kota Kendari yang mengikuti pembinaan karakter di Wahdah Islamiyah Kota Kendari, serta melakukan pengamatan terhadap hal-hal yang berkaitan dengan pembentukan karakter yang dilakukan oleh Wahdah Islamiyah terhadap masyarakat Kota Kendari. Selanjutnya, data yang diperoleh dianalisissecara deskriptif kualitatif. Hasil penelitian menunjukkan bahwa pembentukan karakter yang dilakukan oleh Wahdah Islamiyah terhadap masyarakat Kota Kendari adalah merupakan tujuan yang tidak bertolak belakang dengan tujuan pembentukan karakter yang dicanangkan oleh pemerintah Kota Kendari terhadap masyarakatnya. Dalam rangka meningkatkan keimanan dan ketakwaanmasyarakat Kota Kendari, pemerintah mencanangkan program pembebasan buta aksara Al Qur' an dan perbaikan akhlak masyarakat Kota Kendari. Sejalan dengan apa yang dilakukan oleh Wahdah Islamiyah yang melakukan pembentukan karakter terhadap masyarakat kota kendari dengan menggunakan beberapa pendekatan pembinaan yakni pendekatan pembinaan mental dan spiritual, kepemimpinan, pelatihan, akademik, kompetisi, dan amaliya. Semua pendekatan ini berfungsi untuk menjadikan masyarakat Kota Kendari memiliki nilai-nilai karakter yang baik dan memiliki keimanan serta ketaqwaan yang kuat kepada Allah Subhanahu Wata'ala. Nilai-nilai karakter yang terdapat dalam pembentukan karakter yang dilakukan oleh Wahdah Islamiyah terhadap masyarakat Kota Kendari ini adalah nilai religius, toleransi, disiplin, kerja keras, jujur, menghargai prestasi, peduli lingkungan, peduli sosial dan tanggung jawab. Nilai-nilai pembentukan karaakter tersebut dapat diidentifikasi dari kegiatan- kegiatan yang dilakukan dari masyarakat yang mengikuti pembinaan di Wahdah Islamiyah serta dari pola sikap dan tingkah laku mereka setelah mereka mendapatkan pembinaan karakter yang dilakukan oleh Wahdah Islamiyah Kota Kendari.
\end{abstract}

Kata Kunci: Karakter, Wahdah Islamiyah, masyarakat Kota Kendari.

Abstract: The purpose of this study is to describe the forms, functions, values, and moral change of the people of Kendari City after getting a character education provided by Wahdah Islamiyah. In this study, the data were obtained through 
structured observation and interviews of 12 administrator of Wahdah Islamiyah Kendari and 17 Kendari City resident who participated in character building in Wahdah Islamiyah of Kendari City, and conducted observations on matters relating to character building carried out by Wahdah Islamiyah towards the people of Kendari City. Furthermore, all research objects were analyzed qualitatively descriptive. The results showed that the character building carried out by Wahdah Islamiyah towards the people of Kendari City is a goal that was not contrary to the goal of character building launched by the Kendari City government towards its people. In order to increase the faith and piety of the people of Kendari City, the government has launched a program to liberate the illiteracy of the Qur'an and improve the morals of the people of Kendari City. In line with what was done by Wahdah Islamiyah who did the character building of the city of kendari by using several coaching approaches namely the mental and spiritual coaching approach, leadership, training, academic, competition, and amaliya. All of these approaches function to make the people of Kendari City have good character values and have strong in faith and devotion to Allah Subhanahu Wata'ala. The character values contained in the character building carried out by Wahdah Islamiyah towards the people of Kendari City are religious values, tolerance, discipline, hard work, honesty, respect for achievement, care for the environment, care for the social and responsibility. The values of the formation of these characters can be identified from the activities carried out by the people who participate in coaching in Wahdah Islamiyah as well as from their attitudes and behavior patterns after they get character development done by Wahdah Islamiyah in Kendari City.

Keywords: Character, Wahdah Islamiyah, and community of Kendari City

\section{PENDAHULUAN}

Ormas Islam merupakan salah satu pilar utama dari dakwah secara keseluruhan. Jika dilihat dari proporsinya, maka ormas Islam memiliki fungsi yang cukup besar dalam proses perubahan masyarakat menuju masyarakat yang Islami dan bertaqwa kepada Allah Subhanahu Wata'ala. Ormas Islam telah memberikan kontribusi yang sangat besar dalam pembangunan Negara Indonesia. Oleh karena itu, lahirlah Ormas Islam Wahdah Islamiyah sebagai salahsatu lembaga dakwah dalam melakukan pembinaan serta membentengi umat dari kerusakan- kerusakan budaya barat dan penyimpangan-penyimpangan yangingin mencoba merusak masyarakat dan Negara Indonesia. Perkembangan Dakwah Wahdah Islamiyah yang sangat pesat dirasa tidak memungkinkan lagi lembaga Islam ini bergerak dalam bentuk Yayasan, maka dalam Musyawarah YPWI ke-2, tanggal 1 Shafar $1422 \mathrm{H}$ (bertepatan dengan 14 April 2002 M) disepakati mendirikan organisasi massa (ormas) dengan nama yang sama, yaitu Wahdah Islamiyah (WI).

Wahdah Islamiyah adalah ormas yang berasaskan Islam dengan melakukan gerakan dakwah dantarbiyah Islamiyah (Pendidikan) yang berpedoman pada Al Qur'an dan As Sunnah sesuai pemahaman Ahlussunnah wal Jama'ah (Ash-Shalaf Shalih). Hadirnya Wahdah Islamiyah ini adalah untuk mewujudkan dan membina masyarakat yang beriman dan bertaqwa kepada Allah Subhanahu Wa Ta'ala. Selain itu, Wahdah Islamiyah juga 
bertujuan untuk MenegakkanTauhid dan menghidupkan Sunnah serta memupuk ukhuwah Islamiyah untuk terwujudnya persatuan dalam kehidupan bermasyarakat, berbangsa dan bernegara yang diridhai oleh Allah Subhanahu Wa Ta'ala.

Dalam rangka mewujudkan tujuan tersebut, maka Wahdah Islamiyah melakukan berbagai macam usaha. Diantara usaha yang dilakukan oleh Wahdah Islamiyah adalah menghidupkan usaha penyiaran dan pengembangan dakwah Islamiyah melalui berbagai media dan lapangan serta usaha-usaha pendidikan latihan tenaga juru dakwah, mendirikan dan memakmurkanmasjid serta

melaksanakan fungsi masjid sebagai pusat ibadah, pembinaan dan kebudayaan Islam, mendirikan dan membina sarana-sarana pendidikan agama dan umum yang Islami dalam berbagai jurusan dan jenjangnya baik dalam bentuk formal,informal maupun non formal, mendirikan dan mengembangkan usaha-usaha dalam bidang ekonomi yang halal menurut Islam yang didalamnya tercermin ajaranajaran Islam, melakukan kegiatankegiatan sosial berupa penyantunan kaum dhuafa, fakir miskin dan anak yatim piatu. mendirikan lembagalembaga dan badan-badan usaha lain serta melakukan kerja sama dengan lembaga-lembaga usaha lain yang sesuai dengan maksud dan tujuan organisasi.

Kota Kendari merupakan

ibukota Provinsi Sulawesi Tenggara. Kota yang menjadi pusat perkembangan Perdagangan dan Pelabuhan. Mayoritas penduduk Kota Kendari memeluk agama Islam. Kota Kendari dihuni oleh masyarakat dari Suku Tolaki, Suku Muna, Suku Buton, dan Suku Bugis. Sedangkan penduduk asli Kendari berasal dari Suku Tolaki. Kota Kendari memiliki slogan "Kota Lulo sebagai Kota Bertakwa". Namun dengan kencangnya arus globalisasi yang menggilas masyarakat Kota Kendari, slogan tersebut kini hanya sekedar nama dan jauh dari apa yang diharapkan. Bahkan sebaliknya tagline tersebut kontras dengan rusaknya akhlak generasi muda dan masyarakatnya yang sudah jauh dari nilai-nilai Agama serta maraknya atau menjamurnya Tempat Hiburan Malam (THM) yang bisa mengancam moral dan akidah masyarakat di Kota Kendari. Kendari kota bertakwa serta beriman hanyalah sebuah hiasan yang dibanggakan melalui slogan kosong belaka.

\section{LANDASAN TEORI}

Penelitian ini menggunakan teori pembentukan karakter untuk menganalisis metode atau cara pembentukan karakter. Karakter diartikan sebagai tabiat; watak; sifatsifat kejiwaan, akhlak atau budi pekerti yang membedakan seseorang dengan yang lain (Soerjono Soekanto: 1993) Sementara dalam kamus sosiologi, karakter diartikan sebagai ciri khusus dari struktur dasar kepribadian seseorang (karakter; watak). Karakter yaitu cara berfikir dan berperilaku seseorang yang menjadi ciri khas dari tiap individu untuk hidup dan bekerjasama, baik dalam keluarga, masyarakat dan negara. (Suyanto dan Masnur Muslich: 2011).

Penelitian ini juga menggunakan teori perubahan sosial untuk melihat perubahan sosial dan karakter yang terbentuk melalui pembinaan. Perubahan sosial sebagai suatu variasi cara-cara hidup yang telah diterima, yang 
disebabkan baik karena perubahan kondisi geografis, kebudayaan materiil, komposisi penduduk, ideologi (baca pengertian ideologi) maupun disebabkan karena adanya difusi maupun penemuan penemuan baru dalam masyarakat (baca pengertian masyarakat ) tersebut. Jadi perubahan sosial seca umum dapat depengaruhi oleh lingkungan hidup sekitar (Gillin: 2002).

\section{METODE PENELITIAN}

Penelitian ini adalah kualitatif (lihat Sugiono, 1992:86; Ratna, 2004:47) menghasilkan keterangan atau data yang dapat mendeskripsikan realitas sosial dan kejadian-kejadian yang terkait dengan kehidupan masyarakat.

Jenis data dalam penelitian ini adalah jenis data kualitatif bentuk narasi, uraian, dan butir-butir yang terkait dengan masalah performance ritual pataino itolu. Sumber data bersifat primer dan sekunder. Instrumen penelitian berupa pedoman wawancara. Pengumpulan data dilakukan dengan teknik pengamatan, wawancara mendalam, dan studi dokumen. Dalam penelitian ini, analisis data dilakukan secara deskriptif kualitatif dan interpretatif.

\section{HASIL DAN PEMBAHASAN}

Karakter adalah watak, tabiat, akhlak, atau kepribadian seseorang yang terbentuk dari hasil internalisasi berbagai kebajikan (virtues) yang diyakini dan digunakan sebagai landasan untuk cara pandang, berpikir, bersikap, dan bertindak. Nilai-nilai karakter adalah sikap dan perilaku yang didasarkan pada norma dan nilai yang berlaku di masyarakat, yang mencakup aspek spiritual, aspek personal/kepribadian, aspek sosial, dan aspek lingkungan.
Karakter tidak didapatkan sejak lahir, melainkan muncul dari kebiasaan kehidupan kita sehari-hari. Karakter yang diajarkan dan dipraktekkan dalam pendidikan disebut pendidikan karakter. Dalam pendidikan karakter terdapat berbagai macam karakter yang dapat dikembangkan. Bentuk-bentuk pembinaan pendidikan akhlak dan karakter yang dilakukan oleh Wahdah Islamiyah Kota Kendari antara lain pembinaan Al Qur'an, tarbiyah islamiyah, majelis taklim dan seminar, tadribudduad, pelibatan kepanitiaan dan pelatihan, serta pendidikan formal. Berikut ini hasil wawancara dengan ustadz Idul Male, S.Si.,M.Si.,M.Sc (Ketua Lembaga Pembinaan Pendidikan dan Pengembangan Al Qur'an) Dewan Pimpinan Daerah Wahdah Islamiyah Kota Kendari, mengatakan bahwa:

"Pembinaan yang dilakukan oleh Wahdah Islamiyah beraneka macam bentuknya, diantaranya adalah pembinaan masyarakat agar mereka bisa membaca Al Quran sesuai dengan kaidah tajwid yang benar, tarbiyah islamiyah, juga aktif dalam melakukan kajian umum seperti taklim, diskusi, seminar sampai pada pendidikan formal (TK, SD, SMP, dan SMA), terkhusus kader juga diantara metode bentuk pembinaan dan pendidikan akhlak dan karakternya adalah dengan dilibatkan dalam kerja-kerja kepanitiaan lembaga agar dia terbiasa sekaligus meningkatkan skil yang dia miliki" (Wawancara tanggal 11 maret 2019).

Dari penjelasan informan diatas maka diketahui bahwa bentuk-bentuk pembinaan pendidikan akhlak dan karakter yang dilakukan oleh Wahdah 
Islamiyah Kota Kendari sangat banyak bentuknya. Harapannya adalah lewat pembinaan tersebut dapat membentuk manusia-manusia yang memiliki akhlak dan karakter yang mulia. Semua bentuk pendidikan karakter yang dilakukan oleh Wahdah Islamiyah Kota Kendari senantiasa menanamkan delapan belas nilai-nilai nilai pendidikan karakter yang telah dikeluarkan oleh badan penelitian dan pengembangan pusat kurikulum kementrian pendidikan nasional.

\section{Metode Pembentukan Karakter Wahdah Islamiyah}

1. Pembinaan TPA (Taman Pengajian Anak-anak) Pendidikan Al-Qur'an adalah fondasi bagi pengembangan dakwah selanjutnya. Olehnya itu diantara bentuk pembinaan pendidikan akhlak dan karakter yang dilakukan oleh Wahdah Islamiyah Kota Kendari adalah pembinaan Al Qur'an. Jenis- jenis pembinaan Al Qur'an yang dilakukan oleh Wahdah Islamiyah Kota Kendari sangat berfariasi, disesuaikan dengan usia para peserta. Diantara jenis-jenis pembinaan Al Qur'an yang dilakukan oleh Wahdah Islamiyah Kota Kendari adalah pembinaan TPA (Taman PengajianAnak-anak), DIROSA (Dirasa Orang Dewasa), tahsinul qiro'at, rumah qur'an dan tahfidzul qur'an. Hasil wawancara dengan ustadz Idul Male, S.Si.,M.Si.,M.Sc (Ketua Lembaga PembinaanPendidikan dan Pengembangan Al Qur'an) Dewan

Pimpinan Daerah Wahdah
Islamiyah Kota
mengatakan bahwa:

"Dalam pembinaan Al Qur'an sendiri itu masih terbagi-bagi lagi jenisnya disesuaikan dengan kondisi usia masing-masing, kalau yang dibawah usia 15 tahun dia dimasukkan kedalam pembinaanTPA, yang sudah remaja dan orang tua dia menggunakan dirosa, kalau yang sudah bisa membaca $\mathrm{Al}$ Qur'an hanya saja masih tersendatsendat maka dia dibina dalam program tahsinul qiro'at, yang maudibina secara intensif dalam jangka waktu tertentu dari memperbaiki bacaan sampai dengan mulai menghafal Al Qur'an sesuai dengan kesanggupan bisa masuk di rumah qur'an, ada juga tahfidzul qur'an yang khusus bagi mereka yang siap menghafalkan Al Qur'an secara keseluruhan, semuanya memiliki methode yang berbeda- beda" (Wawancara tanggal 11 maret 2019).

Pengajaran Al-Qur'an bagi anak-anak di TK-TPA harus mendapat perhatian yang serius semua pihak, baik masyarakat, pemerintah, orang tua dan khususnya para pengajar. Para pengajar atau pembina TPA di Wahdah Islamiyah sendiri harus mampu melaksanakan pengajaran dengan baik serta mampu mengelola pengajaran tersebut, sehingga mampu mencetak anak-anak sesuai dengan harapan.

DIROSA (Dirasa Orang Dewasa) Dirosa (Dirasah Orang Dewasa) adalah metode belajar Al Qur'an atau pola pembinaan Islam bagi kaum muslimin pemula (pria wanita; remaja, orang dewasa, kakek nenek; muallaf) yang dikelola secara intensif dan berjenjang. Tujuannya adalah Memberikan kemampuan kepada peserta agar mampu membaca AlQur'an dengan baik, lancar dan benar sesuai dengan kaidah ilmu tajwid serta memberikan pengenalan dan pengajaran tentang dasar-dasar ilmu keislaman. Sasaran dari metode ini adalah pria, wanita, remaja, orang dewasa, kakek nenek; muallaf baik dia 
seorang pengusaha, pegawai instansi pemerintahan/perusahaan,

mahasiswa/pelajar dan guru/dosen yang mendambakan perbaikan bacaan $\mathrm{Al}$ Qur'an. Hasil wawancara dengan ustadz Husein Mubarak (Sekretaris Lembaga Pembinaan Pendidikan dan Pengembangan Al Qur'an) Dewan Pimpinan Daerah Wahdah Islamiyah Kota Kendari, mengatakan bahwa:

"DIROSA merupakan pembinaan Al Qur'an yang cocok kepada semua kalangan, baik pria maupun wanita, metode pengajarannya sangat unik yaitu dengan metode klasikal yakni BATU SIUL (Baca Tunjuk Simak dan Ulang), pesertanya juga harus dibatasi dari 10 sampai 25 orang tidak boleh lebih karena akan sulit pengontrolannya dan waktu belajarnya agar lebih cepat dan tidak mudah dilupakan harus dua kali dalam sepekan" (13 Maret 2019 M). Program pembinaan Al Qur'an dengan menggunakan metode DIROSA adalah program yang tepat untuk di ajarkan kepada para remaja dan orang tua. Selain lebih mudah juga membuat para peserta merasa nyaman dan tertarik untuk tetap istiqomah dalam mempelajari Al Qur'an.

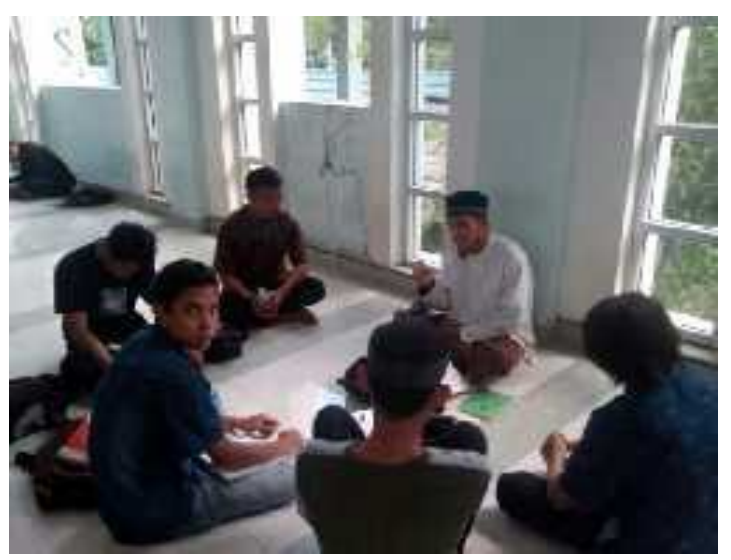

2. Tahsinul Qur'an

Tahsinul Qur'an adalah memperindah dan memperbaiki bacaan al-Qur'an secara benar sesuai dengan kaidah ilmu tajwid. Ilmu Tajwid adalah ilmu tentang tatacara membaca alQur'an yang baik dan benar, baik cara melafalkan huruf, membunyikan hukum nun dan tanwin, bacaan mad, hukum waqaf wal ibtida' dan lain-lain yang terkait dengan cara membaca alQur'an yang baik dan benar. Hasil wawancara bersama Bumnyamin, S.Sos (Juara MTQ 2018 dan kader Wahdah Islamiyah Kota Kendari) beliau mengatakan bahwa:

"Belajar tahsin sangat penting untuk memperbaiki kualitas bacaan, saya tidak akan bisa mendapatkan juara dalam lomba MTQ kalau sebelumnya tidak melewati program tahsinul qiro'ah. Termasuk juga didalam tahsin itu diajarkan masalah tajid danhukumhukum huruf didalamnya, dan yang paling saya suka adalah belajar nada atau lagu dalam membaca Al Qur'an " (15 Maret 2019 M).

Berdasarkan hasil wawancara diatas maka dapat diketahui bahwa program tahsinul qiro'ah adalah program yang sangat membantu masyarakat untuk mempelajari tajwid dan nada dalam membaca Al Qur'an , sehingga Wahdah Islamiyah Kota Kendari memberikan perhatian khusus dalam pembelajaran $\mathrm{Al}$ Qur'an dengan metode tahsinul qiroah.

Kondisi pembinaan Al Qur'an dengan menggunakan program tahsin yang sedang berlangsung dan dimulai dengan pemberian motifasi agar semangat dari salah seorng Ustadz.

\section{Rumah Qur'an}

Pembinaan Al Qur'an yang difokuskan dalam suatu waktu tertentu yang menggabungkan antara perbaikan bacaan Al Qur'an sekaligus mendalami dan menghafalkannya sesuai dengan kesanggupan akan dibimbing dalam satu wadah yang dinamakan rumah Qur'an, 
dan didampingi oleh salah seorang ustadz. Tujuannya agar para peserta bisa lebih fokus dalam mempelajari $\mathrm{Al}$ Qur'an dan juga menghafalkan Al Qur'an dengan target tertentu, waktu yangditentukan antara satu pekan sampai dengan dua pekan. Berikut hasil wawancara bersama Ust. Rizal Haris, S.E (Pembina Rumah Qur'an Ubai bin Ka'ab Lepo-lepo) mengatakan bahwa: "Lama para peserta yang mengikuti pembinaan di Rumah Qur'an bagi orang dewasa tidak terlalu lama antara 1sampai 2 pekan saja dengan mengikuti program 17 hari menghafalkan Al Qur'an, adapun untuk anak dibawah usia 15 tahun yang baru mulai belajar $\mathrm{Al}$ Qur'an maka tergantung sampai kapan mereka bisa lancar dan istiqomah, Rumah Qur'an disediakan untuk masyarakat umum tidak terbatas remaja dan orang tua saja tetapi anak-anak juga bisa” (wawancara, 16 Maret 2019 M).

Berdasarkan hasil wawancara diatas Rumah qur'an menjadi alternatif yang sangat tepat bagi masyarakat kota kendari yang ingin mempelajari dan mendalami serta menghafalkan Al Qur'an. Di rumah Qur'an inilah tempat penanaman nilai-nilai akhlak dan karakter yang dilakukan oleh Wahdah Islamiyah Kota Kendari dalam mewujudkan generasi yang beriman dan bertaqwa serta memiliki budi pekerti yang luhur.

\section{Tahfidz Qur'an}

Program tahfidz Qur'an adalah sebuah program unggulan yang digalakkan oleh Wahdah Islamiyah Kota Kendari. Tahfidz qur'an merupakan tempat dimana generasi muda dididik untuk mampu menghafalkan Al Qur'an secara sempurna dan mutqin tiga puluh juz. Hasil wawancara bersama Ust.
Surimun Al Hafidz (Pembina Tahfidzul Qur'an Abdurrahman bin Auf Poasia) mengatakan bahwa:

"Tahfidzul Qur'an sangat penting dan bermanfaat untuk generasi muda terutama dizaman ini, dimana banyak pemuda sudah mulai meninggalkan $\mathrm{Al}$ Qur'an, mungkin bisa membaca dan sering membaca $\mathrm{Al}$ Qur'an tetapi yangmenghafalkannya sangat jarang dan kalaupun ada sangat sedikit. Padahal menghafalkan Al Quran merupakan pekerjaan yang mulia. Di pesantren tahfidzul qur'an ini generaasi muda dibiasakan untuk menghafalkan Al Qur'an dengan target selama 2 tahun mereka di godok didalam tahfidzul qur'an ini harapannya bisa menghafalkan keseluruhan isi Al Qur'an, selain itu juga mereka dibina dan diajarkan tentang nilai-nilai dalam Al Qur'an sekaligus dilatih untuk terbiasa mengamalkan Al Qur'an" (17 Maret 2019 M).

Hasil wawancara diatas dapat diketahui bahwa Wahdah IslamiyahKota Kendari juga berperan sangat aktif dalam melahirkan dan mencetak generasi muda yang memiliki akhlakul karimah dengan mengamalkan nilainilai Al Qur'an memalui pesantren Al Qur'an Abdurrahman Bin Auf. Saat ini Wahdah Islamiyah Kota Kendari telah mendirikan pondok pesantren tahfidzul qur' an 3 pondok pesantren, diamtaranya 2 pondok pesantren dikhususkan untuk putra dan satu pondok pesantren dikhususkan untuk putri.

\section{Tarbiyah Islamiyah}

Tarbiyah adalah sebuah aktivitas yang sangat dekat dengan aktivis da'wah, dimana aktivitas ini dapat melahirkan banyak kader-kader muslim tangguh yang selalu bersemangat untuk berkorban dan berjuang demi tegaknya 
Agama Allah di muka bumi ini. Tujuan pembinaan yang dilakukan Wahdah Islamiyah Kota Kendari dengan menggunakan metode tarbiyah Islamiyah ada dua yaitu Pertama untuk diri pribadi adalah membentuk pribadi muslim ideal. Kedua untuk masyarakat adalah untuk membentuk masyarakat yang menegakkan agama Allah di muka bumi. Hal ini sebagaimana di katakan oleh ustadz Ir. H. Muhammad Ikhwan Kapai (Ketua Dewan Pimpinan Wilayah Wahdah Islamiyah Sulawesi Tenggara) dalam sebuah kesempatan wawancara. Berikut hasil wawancara bersama ustadz Ir. H. Muhammad Ikhwan Kapai (Ketua Dewan Pimpinan Wilayah Wahdah Islamiyah Sulawesi Tenggara) beliau mengatakan bahwa:

"Tarbiyah itu memiliki 2 tujuan, dan masing-masing tujuan memiliki 5 karakteristik yangharus dipenuhi untuk mencapai tujuan-tujuan itu. Yang pertama adalah untuk diri pribadi adalah membentuk pribadi muslim ideal. Kedua untuk masyarakat adalah untuk membentuk masyarakat yang menegakkan agama Allah di muka bumi. Seseorang pribadi dapat dikatakan sebagai Muslim yang ideal al-Muslim al-Mutamayiz jika memiliki 5 muwashafat atau kaaarakteristik, yaitu Mu'min, Mushlih, Mujahid, Muta'awin dan Mutqin yang disingkat dengan 5 M. Mu'min artinya yang memiliki pemahaman yang benar dan menyeluruh sesuai dengan pemahaman para salafushshalih, memiliki Aqidah yang benar dan kuat, Ahli ibadah yang Ikhlas dan mengikuti Rasulullah Shallallahu Alaili Wasallam dalam ibadahnva, ruhiyah, cinta dan takut kepada Allah serta selau peduli dan prihatin dengan kondisi ummat, merindukan tegaknya dinul Islam, hemiliki akhlak mulia, dan senantiasa beradab dan bermuamalah dengan cara Islam.Muslih artinya yang senantiasa berda'wah dan melakukan perbaikan, dirinya mampu berinteraksi dengan orang lain sebagai obyek da'wah, bisa menjadi agen perubah di manapun dia berada, aktif menjalankan da'wah fardiyah, membangun tatanan yang baik dalam masyarakat bukan menghancurkannya, dan siap menjadi murabbi yang membina masyarakat ke jalan yang di ridhai oleh Allah. Mujahid yaitu orang yang sabar dan mampu menghadapi kondisi yang sulit, berani mengorbankan harta, jiwa dan seluruh potensi yang dimilikinya, memiliki kesiapan untuk berjihad dan merindukan syahid fisabilillah. Muta'awin yaitu menyadari pentingnya beramal jama'i dalam urusan dakwah serta bergabung dalam amal jama'i dengan melibatkan diri, disiplin serta siap dipimpin dan memimpin jika diberi amanah. Mutqin artinya memiliki sifat amanah ketika diberi tugas, siap bertänggung jawab serta menguasai dengan baik amanah yang diberikan kepadanya.Adapun Langkah untuk mewujudkan tujuan tarbiyah yang kedua yakni penegakan agama Allah di muka bumi juga ada 5 yaitu langkah pertanma membentuk rumah tangga muslim yang bersumber dari pribadi muslim dan muslimah yang ideal yang nantinya akan melahirkan anak-anak muslim yang baik keislamannya. Langkah kedua dengan banyaknya keluarga- keluarga muslim maka akan melahirkan jama'ah da'wah yang kuat. Langkah ketiga dengan semakin banyaknya jama'ah dakwah maka akan terbangun masyarakat Islam yang lebih besar. Langkah keempl dengan adanya masyarakat Islam yang sudah memahami Islam dengan benar maka kita dapat menegakkan hukum Islam 
dalam satu bingkai Daulah 1slamiyah, Langkah kelima dengan munculnya Daulah-Daulah Islamiyah yang menegakkan hukum Islam maka kita akan mengembalikan Khilafah Islamiyah" (16 Februari 2019 $\mathrm{M})$.

Berdasarkan hasil wawancara diatas dapat diketahui bahwa tujuan tarbiyah merupakan cita-cita yang semestinya dimiliki oleh seluruh kaum muslimin. Yakni memiliki pribadi muslim yang ideal dan juga mampu menjadikan Agama Allah Subhanahu Wata'ala menjadi agama yang ditegakkan dengan baik serta mengatur seluruh sendi-sendi kehidupan manusia.

\section{Kajian Tematik}

Kajian tematik merupakan suatu kegiatan pembelajaran dengan mengangkat tema khusus untuk memberikan pelajaran kepada peserta dan contoh-contoh aplikasinya dalam kehidupan sehari-hari untuk memberikan pengalaman bermakna bagi para peserta kajian tematik. Materi atau pembahasan yang disajikan dalam kajian tematik disesuaikan dengan tingkat pemahaman peserta kajian. Diantara bentuk-bentuk kajian tematik yang biasa di laksanakan oleh Dewan Pimpinan Daerah Wahdah Islamiyah Kota Kendari adalah Seminar, Taklim Bulanan dan pekanan, Tabligh akbar, bedah buku, diskusi ilmiah, daurah islamiyah, NGOPI (Ngobrol perkara iman) dll. Sebagaimana di katakan oleh ustadz Mardin, S. Hut. (Ketua Departemen Dakwah Wahdah Islamiyah Kota Kendari) dalam sebuah kesempatan wawancara. Berikut hasil wawancara bersama ustadz Mardin, S. Hut. (Ketua Departemen Dakwah Wahdah Islamiyah Kota Kendari)beliau mengatakan bahwa:

"Wahdah Islamiyah Kota kendari melalui departemen dakwah berusaha berinovasi untukmenghasilkan programprogram atau kegiatan-kegiatan yang sesuai dengan tren anak muda dan masyarakat hari ini dengan mengangkat

tema-

temakontemporer dalam rangka menarik minat masyarakat umum agar bisa mengikuti kegiatan yang diselenggarakan oleh Wahdah, dengan melihat fenomena lingkungan masyarakat maka kami dari departemen dakwah Wahdah Islamiyah mengadakan banyak maca-macan kegiatan, contohnya mengangkat sebuah buku untuk dibahas, pelatihan bekam, seminar pemuda, seminar pendidikan, seminar kewirausahaan, tabligh akbar, taklim dan masih banyak lagi. Tujuannya adalah agar masyarakat Kota Kendari bisa memilih kegiatan apa saja yang mereka bisa ikuti karena banyaknya alternatif kegiatan" (12 Februari 2019 M).

Berdasarkan hasil wawancara diatas dapat diketahui bahwa Wahdah Islamiyah selalu melakukan inovasiinovasi dan terobosan-terobosan baru dalam melakukan pencerahan kepada masyarakat Kota Kendari dengan mengadakan banyaknya opsi-opsi kegiatan yang bertujuan untuk menanamkan nilai-nilai karakter yang baik kepada masyarakat Kota Kendari. Banyaknya kegiatan yang ditawarkan oleh Wahdah Islamiyah Kota Kendari dalam kajian tematik ini dapat menjaring seluruh lapisan dan strata masyarakat sesuai dengan tingkat pemahaman dan pekerjaan yang ada didalam masyarakat.

\section{Pelibatan Kader}

Kaderisasi bisa diibaratkan sebagai jantungnya sebuah organisasi, tanpa adanya kaderisasi rasanya sulit 
dibayangkan suatu organisasi mampu bergerak maju dan dinamis. Hal ini karena kaderisasilah yang menciptakan embrio-embrio baru yang nantinya akan memegang tongkat estafet perjuangan organisasi. Kaderisasi berusaha menciptakan kader yang bukan hanya hebat dalam mengerjakan suatu program, tapi lebih dari itu. Kaderisasi haruslah mampumenciptakan kader yang memiliki jiwa pemimpin, memiliki emosi yang terkontrol, kreatif dan mampu menjadi pemberi solusi untuk setiap permasalahan, harus memiliki mental yang kuat dan yang terpenting dapat menjadi seorang teladan bagi anggotanya. Hal ini sebagaimana dikatakan oleh Ust. Yayat Hidayat, S.Pt(Ketua LAZIS SULTRA) dalam wawancara saat berkantor di kantor Wahdah Islamiyah Kota Kendari. Berikut hasil wawancara bersama Ust. Yayat Hidayat, S.Pt (Ketua LAZIS SULTRA) beliau mengatakan bahwa:

"Tujuan kader dilibatkan dalam setiap kegiatan-kegiatan dakawah sangat banyak diantaranya untuk membangkitkan kesadaran bahwa dia bagian dari lembaga perjuangan, dan mengasah atau meningkatkan serta melatih kemampuan dan skil yang ada di setiap kader agar lebih profisional didalam kerja-kerja dakwah" (17 Mei 2019 M).

Hasil wawancara diatas dapat diketahui bahwa tujuan kader dilibatkan dalam setiap kerja-kerja dakwah adalah untuk melatih dan meningkatkan skil kader dalam berorganisasi agar menjadi kader yang profesional dalam menangani setiapkegiatan-kegiatan.

\section{KESIMPULAN}

Berdasrkan deskripsi dan pembahasan hasil penelitian yang telah penulis kemukakan diatas, maka pendidikan akhlak dan karakter yang dilakukan oleh Wahdah Islamiyah Kota Kendari dapat disimpulkan sebagai berikut.

1. Pendidikan akhlak dan karakter yang dilakukan oleh Wahdah Islamiyah Kota Kendari dilakukan dalam beberapa bentuk diantaranya adalah pembinaan Al Quran, Tarbiyah Islamiyah, kajian tematik dan pelibatan kader.

2. Berdasarkan hasil wawancara informan dan observasi yang dilakukan oleh peneliti di Wahdah Islamiyah Kota Kendari maka peneliti menyimpulkan bahwafungsi pendidikan karakter yang dilakukan oleh Wahdah Islamiyah adalah, pertama untuk membentuk karakter dasar masyarakat yang mengikuti pembinaan di Wahdah Islamiyah sehingga kelak menjadi masyarakatmasyarakat yang memiliki perilaku dan sikap yang baik. Kedua, menanamkan jiwa kepemimpinan dan tanggung jawab, kepedulian terhadap sosial dan lingkungan serta kecerdasan intelektual, spiritual dan emosional pada setiap masyarakat yang mengikuti pembinaan di Wahdah Islamiyah. Ketiga, untuk mengembangkan kemampuan masyarakat yang mengikuti pembinaan di Wahdah Islamiyah sehingga kelak menjadi masyarakat yang mandiri dan kreatif serta memiliki cita-cita yang tinggi untuk menjadi agen perubahan kepada yang baik ditengah masyarakat.

3. Nilai-nilai yang terkandung dalam pendidikan akhlak dan karakter yang terdapat didalam Wahdah 
Islamiyah adalah nilai religius, toleransi, disiplin, kerja keras, jujur, menghargai prestasi, peduli sosial, peduli lingkungan, dan tanggung jawab.

4. Perubahan akhlak dan karakter masyarakat yang mengikuti pembinaan di Wahdah Islamiyah setelah mengikuti pembinaan dapat dilihat dari segi keyakinan kepada Tuhan-nya setelah mendapatkan pembinaan akhlak dan karakter yang dilakukan oleh Wahdah Islamiayah Kota Kendari sudah pintar membaca Al Qur'an, rajin untuk sholat, memperhatikan pergaulannya dengan baik, memiliki akhlak mulia serta berpenampilan yang lebih syar'i sesuai dengan yang disyariatkan oleh Allah Subhanahu wata'ala, Serta menjauhi pergaulan bebas serta aktifitas yang lain yang dapat merugikan masa depannya.

\section{DAFTAR PUSTAKA}

Ahmad D.Marimba, 2015. Pengantar Filsafat Pendidikan Islam, Bandung : Al-Ma' arif.

Ahmad Amin, 1975. Etika (Ilmu Akhlak), terj. K.H. Farid Ma'ruf, (Jakarta : Bulan Bintang.

Anonim, 2010. Pemikiran Pendidikan Islam, Kajian Tokoh Klasik dan Kontemporer, Fakultas Tarbiyah IAIN Walisongo, Yogyakarta : Pustaka Pelajar.

Ahmadi, Abu dan Widodo Supriyono. 2003. Psokologi Belajar. Surakarta: PT. Rineka Cipta.

$\begin{array}{cc}\text { Bambang } & \text { Mahirjanto. } \\ \text { Manajemen Dan } & \text { Organisasi }\end{array}$
Dalam Realita Kehidupan, Mandar Maju, Bandung. Bumi Aksara.

Barnawy Umari, 1984. Materi Akhlak, Sala : Ramadhani.

Chester I. Bernard. 2014. Kebudayaan Mentalitas dan Pembangunan. Cetakan ke-11. Jakarta: Gramedia.

Chabib Thoha, Saifudin Zuhri, dkk. 1999. Metodologi Pengajaran Agama, Fakultas

Tarbiyah,Yogyakarta : Pustaka Pelajar.

Departemen Agama RepubliikIndonesia. 1994. Al-Qur'an dan Terjemahnya, Semarang : PT. Kumudasmoro Grafindo.

Drs. H. Malayu, S.P. 2007. Effective Schools and Effective Teachers. Jakarta: Aksara Baru.

Gillin. 2002. Contemporary Sosiological Theories. New York: Harper \& Row.

Hans Garth dan C. Wright Mills. 2002. Terjemajhan Bina Karakter: Panduan Orang tua dan Guru dalam Membentuk Kemandirian dan Kedisiplinan. Yogyakarta: Ar-Ruzz Media.

Hamka Abdul Aziz, 2011. Daur al-Bait fi Tarbiyah ath-Thifl al-Muslim, terj. Ibnu Burdah, "Menumbuhkan Sikap Sosial, Moral dan Spiritual Anak dalam Keluarga Muslim, Yogyakarta : Mitra Pustaka. 
Hamka Abdul Aziz. 2011. Manajemen strategic non profit dalam bidang pemerintahan, gadjah mada university. Yogyakarta. Press.

Hisam-sam, 2017. Konsep dan Model Pendidikan Karakter. Bandung: PT. Remaja Rosda Karya.

Imam Al-Ghazali, 1342. Ihya' Ulumuddin Juz III, Beirut : Dar Ihya al-Kutub al-Ilmiyah.

Ibnu Miskawaih, 1938 H. Musnad Juz II, Beirut : Darul Kutub al Ilmiyah.

J.R. Schermehorn. 2002. Kebudayaan Pembangunan dalam Perspektif Sejarah. Yogyakarta: Gadjah Mada University Press.

James D Mooney.1997. Membangun Pendidikan Karakter Di Sekolah Melalui Kearifan Lokal. MakalahSeminar Kearifan Lokal.

Koentjaraningrat, 1980. Pengantar Ilmu Antropologi. Cetakan ke-6. Jakarta: Aksara Baru.

Marzuki. 2009. Teologi

Pendidikan,Jakarta ; PT. Raja Grafindo Persada.

Muhammad 'Athiyyah Al-Abrasyi, 1970. Prinsip-Prinsip Dasar Pendidikan, Bandung : Pustaka Setia.

M. Ali Hasan, 1988. Tuntunan Akhlak, Jakarta : Bulan Bintang.

M. Daud Ali, 2000. Pendidikan Agama
Islam, Jakarta : PT. RajaGrafindo Persada.

Muhammad Omar, Kamil, 1979. Etika Al-Ghazali, "Etika Majemuk Di Dalam Islam, terj. J. Muhyidin, Bandung : Pustaka.

Muhammad Yunus, 1978. Pendidikan Karakter: Implementasi Aswaja Sebagai Nilai Pendidikan Karakter. Yogyakarta: Pustaka Ilmu.

Muhammad Furqon Hidayatullah, 2010. Sosiologi Perubahan Sosial Perspektif Klasik, Modern, Post Modern, dan Pos Kolonial. Jakarta: PT. Raja Grafindo.

M. Furqon Hidayatullah. 2010. DasarDasar Manajemen Organisasi. Jakarta kencana.

Majid Fakri. 1996. Pembangunan Bangsa tentang Nasionalisme, Kesadaran dan Kebudayaan Nasional. Yogyakarta: Aditya Media.

Ngainun Naim dan Achmad Sauqi. 2014. Makalah manajemen organisasi Islam. Jakarta: PT. Raja Grafindo.

Oliver dan Hasanuddin Sinaga, 2003.Pengantar Studi Akhlak, Jakarta : PT. Raja Grafindo Persada.

Ridwansyah. 2010. Filsafat Pendidikan Islam, Jakarta : Bumi Aksara.

Rachman, 2011. Metodologi Penelitian Pendidikan Moral. Semarang: UNESS Press. 
Copyright (C) 2020 Jurnal Fokus Penelitian Budaya : Masalah-Masalah Kebudayaan dan Masyarakat.

Kajian Budaya Pascasarjana Universitas Halu Oleo Kendari Sulawesi Tenggara, e-ISSN: 2502-3268. Open Access at: ttp://ojs.uho.ac.id/index.php/JPeB

Syarifuddin Jurdi, dkk. 2007. Metodologi Pendidikan Agama, Bandung : Ramadhani.

Suwito, 2004. Akhlak Tasawuf, Jakarta: PT. Raja Grafindo Persada.

Sugiono.2006. Metode Penelitian
Bisnis. Bandung: CV. Alfa Beta.

Sutopo, 2002. Pengantar Penelitian Kualitatif. Sukarta: Universitas Sebelas Maret Press.

Sutarto, 1989. Konsep-konsep Dasar dalam Penelitian Kualitati. 